\title{
Pitcher morphology and pitcher coloring of Nepenthes mirabilis Druce. from East Kalimantan, Indonesia
}

\author{
TRI HANDAYANI", JULISASI TRI HADIAH \\ Research Center for Plant Conservation and Botanic Gardens, Indonesian Institute of Sciences. Jl. Ir. H. Juanda No. 13 Bogor 16122, West Java, \\ Indonesia. Tel.: +62-251-8322187, Fax.: +62-251-8322187, ^email: irtri@yahoo.co.id
}

Manuscript received: 16 August 2019. Revision accepted: 3 September 2019.

\begin{abstract}
Handayani T, Hadiah JT. 2019. Pitcher morphology and pitcher coloring of Nepenthes mirabilis Druce. from East Kalimantan, Indonesia. Biodiversitas 20: 2824-2832. The shape and color of Nepenthes pitchers play an important role in attracting preys. The terrestrial and aerial pitchers have different shapes in accordance with different preys they trap. This species has high potential as an ornamental plant due to the pitcher's varied sizes, shapes and colors, which information of the wild species is inadequate. This study aimed to identify the morphological characters, size, and colors of pitcher and its parts (tendril, pitcher body, lid, peristome, wing) of $N$. mirabilis growing in the wild in East Kalimantan. Samples for morphological observation comprised 90 terrestrial pitchers and 90 aerial pitchers, and samples for pitcher coloring observation comprised 650 terrestrial pitchers and 650 aerial pitchers. The results showed that the shape of terrestrial pitchers were narrowly ovoid in the lower part and cylindrical toward the top. The aerial pitchers were infundibular in the lower part, narrowly ovoid in the middle then cylindrical toward the top. The highest percentage of terrestrial pitcher tendril's color was green and the aerial pitcher tendril's was reddish green. Most pitcher body's color was green in the lower part and green with purple stripes in the upper part on both terrestrial and aerial pitchers (21.07\% and $16.15 \%$, respectively). The wing color of both pitchers was mostly purplish dark red which possessed the highest percentages (30.31\% and $40.64 \%$, respectively). The dominant peristome color of terrestrial pitcher was brownish dark red $(26.15 \%)$, whereas that of the aerial pitcher was purplish dark red (44.19\%). The lid color of both terrestrial and aerial pitchers was mostly purplish dark red (38.92\% and $31.39 \%$ respectively). Bright color was mostly found on the peristome and lid. It was found on $85.38 \%$ of terrestrial pitcher's peristome, $95.22 \%$ of terrestrial pitcher's lid, $81.43 \%$ of aerial pitcher's peristome, and $98.77 \%$ of aerial pitcher's lid. The presence of green color on tendril, pitcher and its parts indicates its function in photosynthesis, whereas the presence of bright color shows its role in capturing preys.
\end{abstract}

Keywords: East Kalimantan, Nepenthes mirabilis, pitcher coloring, pitcher morphology

\section{INTRODUCTION}

Carnivorous plants such as Nepenthes spp., mostly grow in sunny, nutrient-poor and wet environments (Di Giusto et al. 2008; Gaume et al. 2016). They generally produce a poorly developed root system (Pavlovič et al. 2007). These plants fulfill their nutritional needs by capturing preys using their modified leaves called pitchers. The pitchers function to attract, capture and digest preys, mostly insects (Bazile et al. 2015). Nepenthes produces two types of pitchers, namely terrestrial and aerial pitchers (Clarke 2001). Terrestrial pitchers, also known as lower pitchers, are produced by the rosette leaves located on the ground. Aerial pitchers, also known as upper pitchers, are produced by the scrambling leaves. The lower and upper pitchers have different shapes due to different kinds of preys they trap. Nepenthes utilizes their terrestrial pitchers to attract and capture preys living on the ground, while aerial pitchers are used to attract and capture flying insects. The structure of terrestrial and aerial pitchers consists of tendril, body (waxy and digestive zones), lid, peristome and wing (Clarke 2001; Wang et al. 2009).

Nepenthes develops its own mechanism to lure preys, so that its pitchers can capture and digest them. It provides different means to attract preys, such as nectar rewards (Owen et al. 1999; Schaefer and Ruxton 2008; Bauer et al.
2009; Bennett and Ellison 2009; Farre-Armengol 2015), odor (Moran et al. 1999; Bennett and Ellison 2009; Di Giusto et al. 2010), pitcher shape (Gaume et al. 2016), coloration (Moran et al. 1999; Schaefer and Ruxton 2008; Gaume et al. 2016), and environmental factors (Moran 1996; Bauer et al. 2009; Scholz et al. 2010; Bonhomme et al. 2011). Nectar produced by Nepenthes pitchers is a common signal for luring preys (Schaefer and Ruxton 2008; Bauer et al. 2009). Hua and Li (2005) reported that underside of the lid and the pitcher mouth produce a lot of nectarines that attract flying insects to land on the rim.

The shape, size and color of the pitcher play an important role in attracting preys in most Nepenthes (Hua and Li 2005; Bauer 2009). Newell and Nastase (1998) showed that no correlation between prey capture and pitcher size i.e. mouth diameter of Sarracenia purpurea (Sarraceniaceae). Their finding, however, was in contrast to Green and Horner's (2007) that pitcher size in Sarracenia alata was significantly and positively related to daily mass capture of insects. The role of pitcher colors on prey capture is still being debated among carnivorous plant researchers. Green and Horner (2007) found no effect of color variation on prey capture in Sarracenia alata. Wallen (2008) also found that no correlation between species richness and pitcher color in Sarracenia purpurea. Furthermore, Foot et al. (2014) reported that a red 
coloration did not fulfil a prey attraction function or serve as advantageous camouflage in Drosera rotundifolia (Droseraceae). In contrast, Newell and Nastase (1998) found that prey was attracted to Sarracenia purpurea pitchers with greater levels of red venation than green. Schaefer and Ruxton (2008) also reported that preys, mostly flies, captured by $N$. ventricosa increased with increasing red coloration on the pitchers.

Plant coloration is the result of the presence of various pigments. Schaefer and Rolshausen (2005) reported that three pigment classes, namely chlorophyll (green), anthocyanins (red, blue, purple, black) and carotenoids (yellow to red) contributed in various proportions to most color shades on plants. Green is characteristic of the presence of chlorophyll pigments in plants, which is the main pigment used in photosynthesis (Croft and Chen 2017). Close and Beadle (2003) stated that anthocyanin accumulation in parts of plants is closely related to macro nutrient deficiency, specifically the deficiency of nitrogen (N) and phosphorous (P). Thus, red pigmentation is commonly found in leaves of carnivorous plants including Nepenthes, because they grow on poor soil lacking of nutrients (Jurgens et al. 2015). Anthocyanin accumulation is associated with environmental factors, as light, temperature and water (Steyn et al 2002). The relationship between coloration and nectar production on pitchers is still unclear, but striking colors tend to appear in pitcher parts that contain a lot of nectar, such as the lid and peristome (Moran et al. 1999; Bauer and Federle 2009).

Nepenthes mirabilis Druce is one of the most widely known species in the genus, and found widespread in Borneo, including East Kalimantan (Cheek and Jebb 2001; Hua and Li 2005; Handayani et al. 2005). This species is abundant in seasonal habitats, such as swamps. It grows equally common on alkaline and acidic soils. However, this species does not compete well with other abundant Nepenthes species, and is therefore rarely found growing together with other species (Clarke 2001; Handayani 2017). $N$. mirabilis possesses high values to be developed as an ornamental plant due to its large productions of pitchers with varying colors and sizes (Plachno 2007). The colorful pitcher was formed by distribution of bright colors on pitcher parts. Such information on the pitcher coloring of $N$. mirabilis in its natural habitat is lacking. We assumed that the color of pitcher lid and peristome should be more striking than that of other parts as it functions to attract preys. In addition, other parts with striking colors such as red, purplish, yellow, probably also possess the same function. The purpose of this study was to identify the pitcher's morphological characters, size, and colors occurring in every part of the pitcher (tendril, pitcher body, lid, peristome and wing) of Nepenthes mirabilis Druce from East Kalimantan. Understanding the pitcher's morphology, size, and colors will be useful in the propagation of this species, as well as in understanding the functions of colors and parts of the pitchers.

\section{MATERIALS AND METHODS}

\section{Study area}

This research was carried out at Muara Badak District, Kutai Kartanegara Regency, East Kalimantan Province. The altitude of the study site is about $720 \mathrm{~m}$ asl, relative humidity $40-64 \%$, temperature $31-43^{\circ} \mathrm{C}$, soil $\mathrm{pH} 5.1-6$ and soil moisture $30-50 \%$. This study was carried out using purposive sampling where $N$. mirabilis found. Observations were done at 15 plots of $10 \times 10 \mathrm{~m}^{2}$. Local micro climate was measured in each plot including temperature, soil $\mathrm{pH}$ and humidity. Observed pitchers (terrestrial and aerial) were all sampled within the plots.

\section{Observation on pitcher morphology}

Several parameters of pitcher morphology and color distribution were observed and recorded. Both terrestrial and aerial pitchers, each consisting of 90 pitchers, were sampled for observation on pitcher morphology. The shapes and sizes of the pitchers and their parts were measured, including lengths of tendril and pitcher, pitcher's upper and lower circumferences, wing's width, mouth's length and width, lid's length and width, and spur's length (Figure 1). The length of tendril was measured between the tip of lamina and the lowest part of pitcher body. The length of pitcher was measured between the lowest part of pitcher body (at the point of tendril's attachment) to the tip of peristome (Moran et al. 1999). The pitcher's upper circumference was measured at biggest part of the upper body and the pitcher's lower circumference was measured at biggest part of the lower body. Mouth's length was measured at the longest part of the mouth, and the mouth's width was measured at the widest part of the mouth. Lid's length was measured at the longest part of the lid, and lid's width was measured at the widest part of the lid. Spur's length was measured from the attachment of spur to peristome to the tip of the spur. The shapes and sizes of tendril and pitcher were observed and recorded by naked eyes using a ruler and a camera.

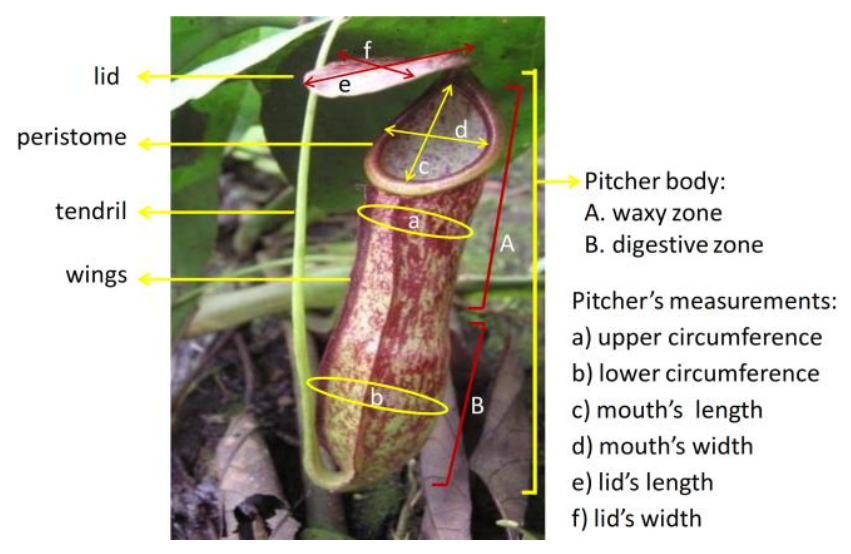

Figure 1. Pitcher's parts and measurements 


\section{Observation on pitcher color}

Observation on pitcher color was carried out for both terrestrial and aerial pitchers. As many as 650 of each terrestrial and aerial pitchers were used as observation samples. The pitcher coloring was observed for tendril, pitcher body, lid, peristome and wing. Color was determined using the horticultural color chart (Royal Horticultual Society), including single color or mixed color. Color observation included primary and secondary colors. Primary color was color that covered most parts of the pitcher. Secondary color was color that covered less parts of the pitcher. In addition to primary and secondary colors, colors appeared on patches, stripes or spots were also identified. If there was only one dominant color, the pitcher was then named by a single color, such as green or dark red. If there were more than one color, the pitcher was then named by the present color combinations, such as purplish red. The pitcher colors were observed visually (adopted from Wallen 2008). We categorized pitcher colors based on the color codes on RHS (Table 1).

\section{Data analysis}

Data gathered on this study were collated and analyzed using an MS Excel spreadsheet.

\section{RESULTS AND DISCUSSION}

\section{Pitcher morphology of Nepenthes mirabilis Druce}

The terrestrial and aerial pitchers of N. mirabilis from Muara Badak slightly varied morphologicaly in size and color, but similar in their shapes. Both pitchers arose from tendril. Almost all terrestrial pitchers tended to be ovoid in the lower part and cylindrical in the upper part, with two prominent wings on the adaxial side. The aerial pitcher looked more or less similar to terrestrial pitcher but more slender and rather infundibuliform in the upper part and without fringed wings on the adaxial side. The size of terrestrial pitcher was more or less the same as the aerial pitcher.

Terrestrial pitcher. The terrestrial tendril was $0.5-26$ $\mathrm{cm}$ long, straight, mostly green. The terrestrial pitcher was narrowly ovoid in the lower part and cylindrical in the upper part, 1-16 cm long. The upper circumference was 2$10 \mathrm{~cm}$ and the lower circumference was $2-12 \mathrm{~cm}$. The terrestrial pitcher was usually equipped with two fringed wings of $0.1-0.3 \mathrm{~mm}$ wide running from pitcher's top to bottom. The pitcher's mouth was round to ovate, slightly oblique, $0.5-4 \mathrm{~cm}$ long and $0.5-3 \mathrm{~cm}$ wide. The peristome was flattened, ovate at the edges, and equipped with rather coarse teeth. The lid was orbicular to ovate, $0.5-4.5 \mathrm{~cm}$ long and $0.5-3 \mathrm{~cm}$ wide. The spur which was located at the base of the pitcher lid was $0.2-0.8 \mathrm{~cm}$ long.

The aerial pitcher of $N$. mirabilis is very much alike the terrestrial pitcher. The aerial tendril was 6-28 cm long, wavy or occasionally circular, mostly reddish green. The aerial pitcher was infundibular in the lower part, narrowly ovoid in the middle and cylindrical toward the top, 4.5-18 $\mathrm{cm}$ long. The upper circumference was $2-10 \mathrm{~cm}$ and the lower circumference was $2-12 \mathrm{~cm}$. There were no fringed wings on aerial pitchers as it was reduced to ribs. The pitcher's mouth was round to ovate, $1.1-5.0 \mathrm{~cm}$ long and $1.1-4.0 \mathrm{~cm}$ wide. The peristome was slightly flattened, ovate at the edges, and equipped with rather coarse teeth. The lid was round to ovate, $1.1-4.0 \mathrm{~cm}$ long and $1.1-4.0 \mathrm{~cm}$ wide. The spur was $0.2-1 \mathrm{~cm}$ long.

Pitcher size. The size of terrestrial pitchers was slightly varied to that of aerial pitchers. The percentage of pitchers with ranges of height, upper circumference and lower circumference was presented in Table 2 . The table showed that in general terrestrial pitcher was shorter than aerial pitcher. Most of the terrestrial pitchers (33.3\%) was 6.1-8.0 $\mathrm{cm}$ high, whereas most of the aerial pitchers $(33.3 \%)$ was $10.1-12.0 \mathrm{~cm}$ high.

The upper circumference of the terrestrial pitcher is generally smaller than that of the aerial pitcher. However, the lower circumference of the terrestrial pitcher is larger than that of the aerial pitcher. Most terrestrial pitchers had the lower circumference of $6.1-8.0 \mathrm{~cm}(44.5 \%)$, whereas most aerial pitchers had the lower circumference of 4.1-6.0 $\mathrm{cm}$ (58.9\%). In other words, aerial pitcher was more slender than terrestrial pitcher, which was necessary as it was lighter to be carried by the tendril. Moreover, light pitcher was more resistant to wind blows than the heavier one (Clarke 2001). The bigger bottom of terrestrial pitcher was related to the pitcher's function that was to catch preys on the ground, such as ants. The bigger the pitcher bottom is, the more number of preys can be captured. In addition, pitcher that is above the ground has little effect on capture of flying prey (Moran et al. 1999).

Table 1. Pitcher coloring based on RHS

\begin{tabular}{ll}
\hline Color & Color codes on RHS \\
\hline Light yellow-yellow green & Yellow-green 145D, yellow-green 149D, yellow-green 150D. \\
Light green & Blue-green 124D, blue-green 177 C, \\
Green & Green 129C, 130B, 130C, 132D, 134C, 134D, 135D, 138B, 138C, 140C, 143C. \\
Red & Red 51D, red 51C. \\
Dark red & Greyed-red 178A, greyed-red 180B, 181C \\
Purplish red & Red-purple 65C, 62D, 68A, 69D, 73A, 73C, 73D, N74C, greyed-purple 184A, 185D. \\
Purple & Purple 75C, 75D, N78C, N77C, \\
\hline
\end{tabular}


Table 2. The percentage of Nepenthes mirabilis pitchers with ranges of height, upper circumference and lower circumference

\begin{tabular}{|c|c|c|c|c|c|c|c|c|c|c|c|c|}
\hline \multirow{3}{*}{ Size $(\mathbf{c m})$} & \multicolumn{6}{|c|}{ Terrestrial pitchers } & \multicolumn{6}{|c|}{ Aerial pitchers } \\
\hline & \multicolumn{2}{|c|}{ Height } & \multicolumn{2}{|c|}{$\begin{array}{c}\text { Upper } \\
\text { circumference }\end{array}$} & \multicolumn{2}{|c|}{$\begin{array}{c}\text { Lower } \\
\text { circumference }\end{array}$} & \multicolumn{2}{|c|}{ Height } & \multicolumn{2}{|c|}{$\begin{array}{c}\text { Upper } \\
\text { circumference }\end{array}$} & \multicolumn{2}{|c|}{$\begin{array}{c}\text { Lower } \\
\text { circumference }\end{array}$} \\
\hline & $\begin{array}{c}\text { No. of } \\
\text { pitchers }\end{array}$ & $\%$ & $\begin{array}{c}\text { No. of } \\
\text { pitchers }\end{array}$ & $\%$ & $\begin{array}{c}\text { No. of } \\
\text { pitchers }\end{array}$ & $\%$ & $\begin{array}{c}\text { No. of } \\
\text { pitchers }\end{array}$ & $\%$ & $\begin{array}{c}\text { No. of } \\
\text { pitchers }\end{array}$ & $\%$ & $\begin{array}{c}\text { No. of } \\
\text { pitchers }\end{array}$ & $\%$ \\
\hline $0.1-2.0$ & 3 & 3.4 & 4 & 4.5 & 1 & 1.1 & & & 1 & 1.1 & 3 & 3.3 \\
\hline 2.1-4.0 & 8 & 8.9 & 27 & 30 & 5 & 5.6 & & & 8 & 8.9 & 15 & 16.7 \\
\hline $4.1-6.0$ & 10 & 11.1 & 39 & 43.3 & 32 & 35.6 & 4 & 4.4 & 19 & 21.2 & 53 & 58.9 \\
\hline $6.1-8.0$ & 30 & 33.3 & 19 & 21.1 & 40 & 44.5 & 9 & 10 & 46 & 51.1 & 16 & 17.8 \\
\hline $8.1-10.0$ & 25 & 27.8 & 1 & 1.1 & 11 & 12.2 & 17 & 18.9 & 14 & 15.6 & 3 & 3.3 \\
\hline $10.1-12.0$ & 9 & 10,0 & & & 1 & 1.1 & 30 & 33.3 & 2 & 2.2 & & - \\
\hline $12.1-14.0$ & 4 & 4.4 & & & & & 20 & 22.2 & & & & \\
\hline $14.1-16.0$ & 1 & 1.1 & & & & & 5 & 5.6 & & & & \\
\hline $16.1-18.0$ & & & & & & & 5 & 5.6 & & & & \\
\hline
\end{tabular}

Table 3. The percentage of Nepenthes mirabilis pitchers with ranges of mouth's length and width

\begin{tabular}{|c|c|c|c|c|c|c|c|c|}
\hline \multirow[t]{3}{*}{ Size $(\mathbf{c m})$} & \multicolumn{4}{|c|}{ Terrestrial pitchers } & \multicolumn{4}{|c|}{ Aerial pitchers } \\
\hline & \multicolumn{2}{|c|}{ Mouth length } & \multicolumn{2}{|c|}{ Mouth width } & \multicolumn{2}{|c|}{ Mouth length } & \multicolumn{2}{|c|}{ Mouth width } \\
\hline & No. of pitchers & $\%$ & No. of pitchers & $\%$ & No. of pitchers & $\%$ & No. of pitchers & $\%$ \\
\hline $0.1-0.5$ & & & 7 & 7.8 & & & & \\
\hline $0.6-1.0$ & 4 & 4.5 & 18 & 20.0 & & & 2 & 2.2 \\
\hline $1.1-1.5$ & 13 & 14.4 & 25 & 27.8 & 5 & 5.6 & 6 & 6.7 \\
\hline $1.6-2.0$ & 23 & 25.6 & 27 & 30.0 & 12 & 13.3 & 20 & 22.2 \\
\hline $2.1-2.5$ & 28 & 31.1 & 12 & 13.3 & 20 & 22.2 & 30 & 33.3 \\
\hline $2.6-3.0$ & 12 & 13.3 & 1 & 1.1 & 29 & $32 . .2$ & 24 & 26.7 \\
\hline $3.1-3.5$ & 8 & 8.9 & & & 12 & 13.3 & 3 & 3.3 \\
\hline $3.6-4.0$ & 1 & 1.1 & & & 4 & 4.5 & 5 & 5.6 \\
\hline $4.1-4.5$ & 1 & 1.1 & & & 3 & 3.3 & & \\
\hline $4.6-5.0$ & & & & & 5 & 5.6 & & \\
\hline
\end{tabular}

Table 3 shows the data of mouth's length and width of terrestrial and aerial pitchers. The aerial pitcher had a wider mouth than terrestrial pitcher. Most terrestrial pitcher's mouth was $2.1-2.5 \mathrm{~cm}$ long $(31.1 \%)$ and $1.6-2.0 \mathrm{~cm}$ wide (30\%). Most aerial pitcher's mouth was 2.6-3.0 cm long $(32.2 \%)$ and $2.1-2.5 \mathrm{~cm}$ wide $(33.3 \%)$. The narrow mouth of terrestrial pitcher is in accordance with its function that is to capture preys on the ground, such as ants or other small animals. When the preys search for nectar in underside of the lid or peristome, they will slip and fall into the pitcher even if the mouth is narrow due to the slippery surface. For aerial pitcher, on the other hand, a wide mouth is preferred to catch flying preys more easily.

\section{Pitcher coloring of Nepenthes mirabilis Druce}

The presence of colors in plants is related to some functions they serve, such as green color of leaves with photosynthesis, colors of flowers with pollinator (Schaefer and Rolshausen 2005). This study observed some variation on colors of the tendrils and parts of $N$. mirabilis pitchers from Muara Badak. The colors of terrestrial and aerial pitchers of this species were varied, and this may also related to the roles they play.

Tendril is a further growth of the midrib. It elongates along with leaf growth and the tip will develop into a pitcher. The tendril position of terrestrial pitcher is different from that of aerial pitcher (Clarke 2001). Tendril of terrestrial pitchers of $N$. mirabilis observed in Muara Badak is straight or wavy when it stands alone, or curly when there are other pitchers growing together/nearby; and is attached at the adaxial side of the pitcher. The tendril of aerial pitcher is always curly and attached at the abaxial side of the pitcher. Tendril may function to support the aerial pitcher against the wind, and also to support the growth of the climbing stem.

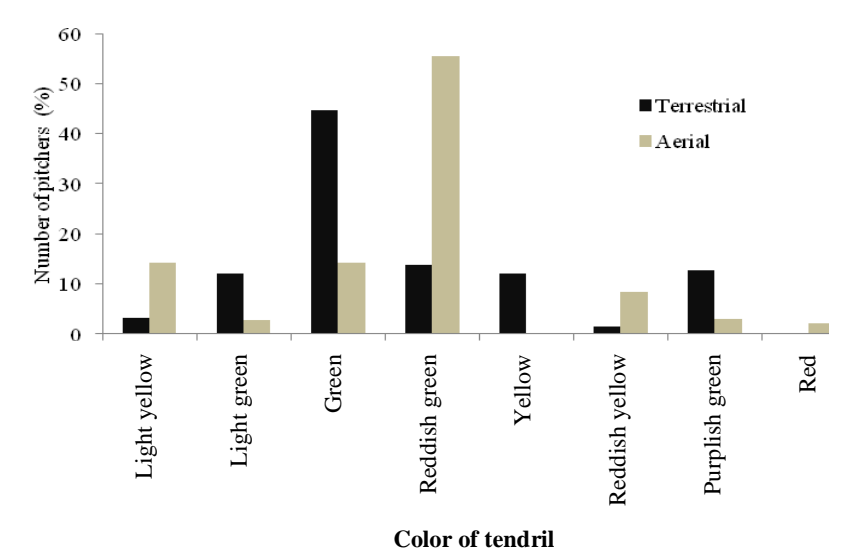

Figure 2. Color variation of tendril of terrestrial and aerial pitchers of Nepenthes mirabilis 
This study observed eight colors of tendril in both terrestrial and aerial pitchers (Figure 2). The color of terrestrial tendril was mostly green, whereas that of aerial tendril was mostly reddish green. Bright colors such as reddish, red and yellow, were also present on the tendrils. Green and bright colors may present alone or together with other colors. Among the 650 observed terrestrial tendrils, $83.38 \%$ contained green color, $56.76 \%$ of which was a single color (green only); $43.24 \%$ contained bright colors, $16.62 \%$ of which was present as a single color. As for the observed aerial tendrils, $75.39 \%$ contained green color, $17.08 \%$ of which was a single color (pure green); and $82.92 \%$ contained bright colors, $24.61 \%$ of which was present as a single color.

The green color of leaf is usually associated with chlorophyll content that plays an important role in photosynthesis Pavlovič et al. (2007). In accordance with that, tendrils of Nepenthes also functions in photosynthesis. As the green content of terrestrial tendril is higher than that of the aerial tendril, therefore the former plays more roles in the photosynthesis rather than to lure preys as the aerial tendril does. The presence of more bright colors in aerial tendrils is presumably related to the aerial pitcher function for attracting prey. The function of aerial pitchers is to capture insects, especially flying insects (Moran et al.1999; Clarke 2001). Having bright colors on tendril will ease insects to recognize the aerial pitcher.

Pitcher body. A pitcher of Nepenthes spp. is the further growth of the leaf tip. A pitcher consists of several parts, namely: pitcher body, lid, peristome and wing. Pitcher body is the most interesting part of the pitcher for its form, size and color. It is covered by bright colors, such as green, red, dark red and yellow, or combination of the colors. Some sample photos are shown in Figure 3.

Observed color variations of terrestrial and aerial pitcher bodies were presented in Table 4. There were 10 color combinations of the terrestrial pitchers and 13 color combinations of the aerial pitchers. Almost all terrestrial pitchers contain green color $(86.92 \%)$, but only $8.77 \%$ of the sampled pitchers was pure green. The most dominant color combination was green on below part and green with purple stripes on upper part $(21.07 \%)$. Bright colors (red, purple, light yellow) were found on $91.23 \%$ of the sampled terrestrial pitchers, $13.08 \%$ of which was pure purplish red and light yellow with no green.

Green color was also found in most color combinations of the sampled aerial pitcher. $80.77 \%$ of the aerial pitchers contained green color, and $73.07 \%$ with bright color. $26.93 \%$ of the sampled pitchers was pure green, and $19.23 \%$ was bright colors without green. The aerial pitcher bodies were dominated by two color combination (each $16.15 \%$ ), namely combination of green below part and green with purple stripes upper part, and combination of green with bright red irregular spots below and upper part.

This study revealed that terrestrial pitcher body contains more bright and green colors than aerial pitcher body does.
This implies that terrestrial pitcher plays more roles on photosynthesis and capturing preys than aerial pitcher does. The green color on the body pitcher shows the presence of chlorophylls. The presence of red, purplish and brownish dark red color in the pitcher body indicates the presence of anthocyanin. This pigment was not only found on pitcher body but also on almost other parts of the pitcher. As a pitcher is the further growth of leaf, naturally it also functions for photosynthesis. Although the pitcher body produces nectar, it is not the main nectar producer of the plant. Insects visit the pitcher for the color of the pitcher body, and will eventually slip and fall into preys. However, further research are required to see whether pitcher color really does function to lure preys, or it is merely an adaptive behavior of the plant growing on soil which lacks nitrogen. Close and Beadle (2003) and Jurgens et al (2015) stated that anthocyanin accumulation can be used as an indication of symptoms of nitrogen or phosphorus deficiency.

Pitcher lid keeps the pitcher fluid inside the pitcher from dust, rainwater and other contaminants; and reduces the evaporation of the pitch fluid (Wang et al. 2009). It also has an important contribution to capture preys. Merbach et al. (2001) reported that the lower surface of pitcher lid of $N$. mirabilis produces nectar to attract insects. In addition, the upper surface of the lid is equipped with striking colors to attract visiting insects. The reward offered by the pitcher will trigger insects to visit the pitcher. The slippery lower surface of the lid, however, will cause the visiting insects to slip and fall into the pitcher (Figure 4A).

There were ten color combinations on terrestrial pitcher lids and seven color combinations on aerial pitcher lids (Figure 5). Out of the 650 sampled terrestrial pitchers, $23.85 \%$ of the observed lids contained green color, and $95.22 \%$ contained bright colors. Out of the 650 sampled aerial pitchers, the observed lids containing green color was $32.92 \%$, and bright colors was $98.77 \%$. Most lids of both terrestrial and aerial pitchers contained purplish dark red color. The lid of aerial pitcher had slightly more bright colors than that of terrestrial pitcher $(98.77 \%$ and $95.22 \%$, respectively), which was probably related to the function of aerial pitcher to attract flying preys. Striking colored lid will be more easily recognized by insect visitors. The presence of bright colors on terrestrial pitcher lids, which nectar is the main mean to capture preys on the ground, shows that it is also another mean to attract preys. It is pitcher's strategy in guiding preys to the nectar on the lid. Bright colors invite more preys to visit the pitchers.

Some pitchers, however, do not use bright colors to attract preys. In the case of pure green pitchers, they use nectar produced on the underside of lid as the main insect attraction to visit the pitchers. Similar to the presence of green color in other parts of the pitchers, the presence of green color in the lid shows that the lid also functions in photosynthesis due to the chlorophylls it content. 



Figure 3. Color variation of pitcher body of terrestrial (A-D) and aerial (E-H) pitchers of Nepenthes mirabilis: (A) green with purplish red irregular spots below and upper part, (B) purplish red both below and upper part, (C) green below part, green with purple stripes upper part, (D) green both below and upper part, (E) purplish red both below and upper part, (F) green both below and upper part, (G) green with bright red irregular spots below and upper part, $(\mathrm{H})$ green in 1/5 below part, purplish red upper part. Scale bar: $1 \mathrm{~cm}$.
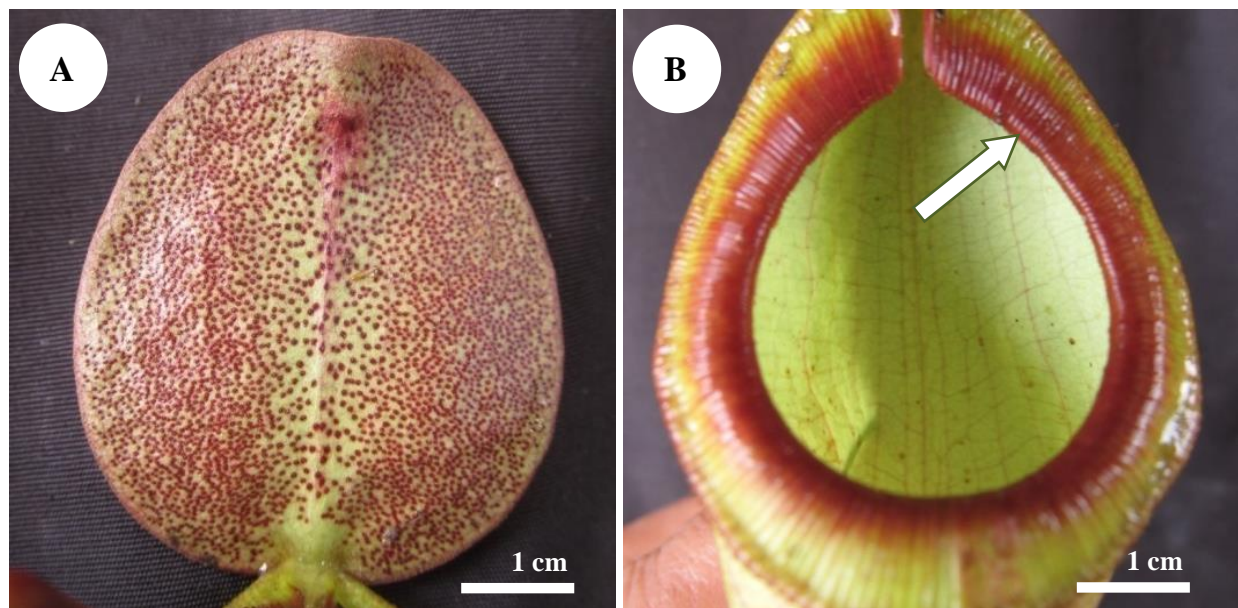

Figure 4. Underside lid producing nectar (A) and pitcher peristome of Nepenthes mirabilis (B). White arrow showing downwardpointing teeth 
Table 4. Color variation found on terrestrial and aerial pitcher bodies of Nepenthes mirabilis

\begin{tabular}{|c|c|c|}
\hline Colors of pitcher body & $\begin{array}{l}\text { Terrestrial pitchers } \\
(\%)\end{array}$ & $\begin{array}{c}\text { Aerial pitchers } \\
(\%)\end{array}$ \\
\hline Green below part, dark red upper part & 12.46 & \\
\hline Green below part, green with purple stripes upper part & 21.07 & 16.15 \\
\hline Green both below and upper part & 8.77 & 9.08 \\
\hline Green with purplish red irregular spots below and upper part & 11.54 & \\
\hline Green below part, yellowish red upper part & 8.31 & \\
\hline Green below part, brownish dark red upper part & 12 & \\
\hline Green below part, purple irregular spots upper part & 11.54 & \\
\hline Green with purple stripes below and upper part & 1.23 & \\
\hline Light yellow below and upper part & 0.31 & \\
\hline Purplish red both below and upper part & 12.77 & 2.15 \\
\hline Green with bright red irregular spots below and upper part & & 16.15 \\
\hline Dark green below part, light green upper part & & 4.46 \\
\hline Green with purple irregular spots & & 3.08 \\
\hline $\begin{array}{l}\text { Green below and upper part with a circular red line at the base of upper } \\
\text { part. }\end{array}$ & & 1.23 \\
\hline Green in $1 / 5$ below part, purplish red upper part & & 10.31 \\
\hline $\begin{array}{l}\text { Green below part, green with red spots upper part with a circular red line in } \\
\text { the base of upper part. }\end{array}$ & & 3.69 \\
\hline Green below part, light red upper part & & 3.23 \\
\hline Light yellow left side on below part, yellowish red right side on upper part & & 6.46 \\
\hline Light yellow below part, dark red upper part & & 10.62 \\
\hline Light green both below and upper part & & 13.39 \\
\hline
\end{tabular}



Figure 5. Color variations of terrestrial and aerial pitcher lids of Nepenthes mirabilis

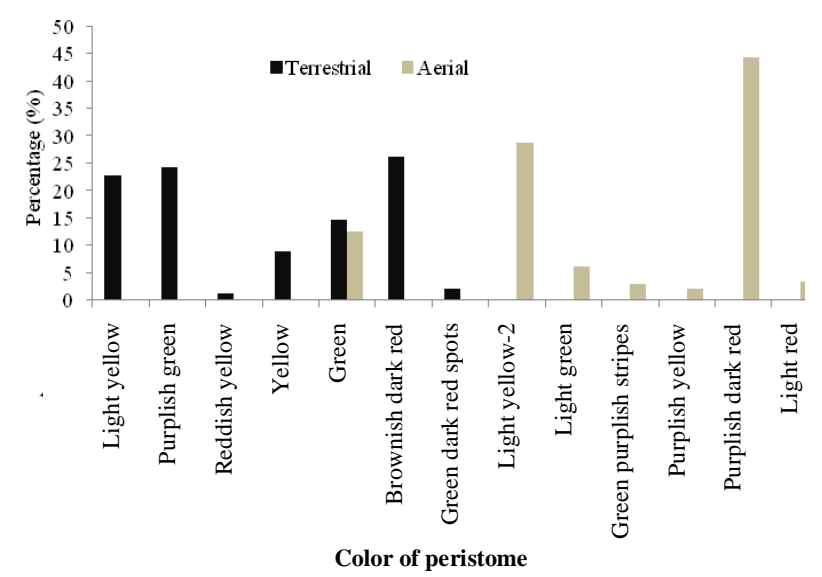

Figure 6. Color variations of terrestrial and aerial pitcher peristomes of Nepenthes mirabilis

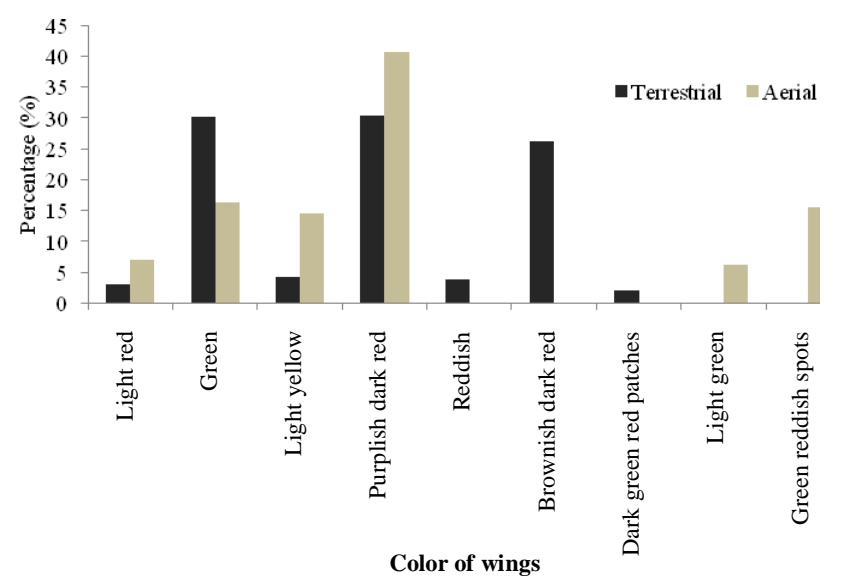

Figure 7. Color variations of terrestrial and aerial pitcher wings of Nepenthes mirabilis

Pitcher peristome plays an important role in attracting preys due to its nectar production and striking colors. Peristome's role in capturing preys would be more effective in rainy season when the condition is wet. Bauer and Federle (2009) reported the capture rates of ants reached more than $80 \%$ under humid conditions as the peristome became extremely slippery.

There were 12 color combinations for both terrestrial and aerial pitcher peristomes (Figure 6), namely purplish green, reddish yellow, yellow, brownish dark red, green dark red spotted (terrestrial); light green, green purplish striped, purplish yellow, purplish dark red, light red (aerial); green and light yellow (both). Out of the 650 sampled terrestrial pitchers, $41.08 \%$ of the pitchers had peristomes containing green color, $14.62 \%$ of which was pure green. $85.38 \%$ of the terrestrial pitcher peristomes 
contained bright colors, and $58.92 \%$ was bright color only with no green. The most common color of terrestrial pitcher peristome was brownish dark red (26.15\%), followed by purplish green color $(24.31 \%)$.

Out of the 650 sampled aerial pitchers, $21.53 \%$ of the pitchers had peristomes containing green color, $18.61 \%$ of which was pure green. $81.43 \%$ of the samples contained bright colors, $78.51 \%$ of which was bright colors only with no green. Most aerial pitcher peristomes was purplish dark $\operatorname{red}(44.15 \%)$.

Similar to the results of observations on the other parts of pitcher, the presence of chlorophylls on green color related to photosynthesis, and anthocyanins on bright colors related to prey capturing. This observation showed that peristome of both terrestrial and aerial pitcher plays more roles in luring preys as they have more bright colors. Moreover, the presence of bright color eased visiting insects to find nectar on the peristome. Bauer et al. (2009), Bennett and Ellison (2009), Clarke (2001), Merbach et al. (2001), and Schaefer and Ruxton (2008) reported that peristomes produce nectar to attract insects, with the most nectar produced in the downward curved part (Newell and Nastase 1998). Peristome's function as a prey trap is also supported by its structure that is convex, bent, with downward-pointing teeth above the waxy zone (Figure. 4B).

Pitcher wing of terrestrial pitcher is fringed, while that of aerial pitchers is not fringed but reduced to ribs. The differences in the wing shape are presumably an adaptation of the plant to attract preys. However, further research are required to see whether pitcher wing really does function to attract preys. Clarke (2001) reported that the fringed wing of terrestrial pitcher act as a ladder for visiting insects to reach the top of the pitcher (i.e.lid, peristome). On the other hand, the wing of aerial pitcher no longer functions as a ladder or the path for visiting insects, so it is reduced to ribs.

There were seven color combinations of terrestrial pitcher wings and six color combinations of aerial pitcher wings (Figure 7). Out of the 650 sampled terrestrial pitchers, $32.30 \%$ of the pitchers had wings with green color only and no other colors at all, while $67.70 \%$ of the pitchers had wings with bright colors only and no green. Most terrestrial pitchers had purplish dark red wings $(30.31 \%)$, followed by green $(30.15 \%)$.

The wing of aerial pitchers formed a line from the base of the pitcher body to the peristome. Out of the 650 sampled aerial pitchers, $38 \%$ of the pitcher wings contained green color, $16.31 \%$ of which was pure green. Wings with bright colors were $77.72 \%$ and $62.18 \%$ of the aerial wings was bright colors only (no green). Most aerial pitchers had purplish dark red wings (40.64\%).

This observation on the pitcher wings showed similar results to the observation on the other parts of pitcher regarding the presence of chlorophylls and anthocyanins. The pitcher wings apparently play more roles in attracting preys than in photosynthesis as they posses more bright colors. This function was shown more clearly by aerial pitcher wings which were mostly bright colored.
In summary, the present study showed that terrestrial and aerial pitchers of $N$. mirabilis from Muara Badak, East Kalimantan, varied morphologically in size and color, but were similar in shape. Colors of tendril and all parts of both terrestrial and aerial pitchers showed that both tendril and pitchers function in photosynthesis as well as attracting preys. Green color mostly occurred on pitcher body ( $86.92 \%$ on terrestrial pitchers, $80.77 \%$ on aerial pitchers), and bright colors occurred mostly on the lid of both pitchers $(95.22 \%$ and $98.77 \%$ respectively). The high percentage of bright color occurrence on the pitcher lid played a role to attract preys, as well as to ease insect visitors to find nectar on the pitcher.

\section{REFERENCES}

Bauer U, Federle W. 2009. The insect-trapping rim of Nepenthes pitchers: Surface structure and function. Plant Signal Behav 4 (11): 1019-1023.

Bauer U,Wilmes C, Federlei W. 2009. Effect of pitcher age on trapping efficiency and natural prey capture in carnivorous Nepenthes rafflesiana plants. Ann Bot 103: 1219-1226.

Bazile V, Moguedec LM, Marshall D, Gaume L. 2015. Fluid physicochemical properties influence capture and diet in Nepenthes pitcher plants. Ann Bot 115: 705-716.

Bennett KF, Ellison M. 2009. Nectar, not color, may lure insects to their death. Biol Lett 5: 469-472

Bonhomme V, Pelloux-Prayer H, Jousselin E, Yoe, Forterre, Labat JJ, Gaume L. 2011. Slippery or sticky? Functional diversity in the trapping strategy of Nepenthes carnivorous plants. New Phytol 191: 545-554

Cheek M, Jebb M. 2001. Nepenthaceae. Flora Malesiana, Series I, Vol. 15. $164 \mathrm{pp}$.

Clarke C. 2001. Nepenthes of Sumatra and Peninsular Malaysia. Natural History Publication. Kota Kinabalu, Malaysia.

Close D, Beadly CL. 2003. The Ecophysiology of foliar anthocyanin. Bot Rev 69 (2): 149-161.

Croft H, Chen JM. 2017. Leaf Pigment Content. University of Toronto, Toronto, ON, Canada. DOI: 10.1016/B978-0-12-409548-9.10547-0A.

Di Giusto B, Bessière J-M, Guéroult M, Lim LBL, Marshall DJ, Hossaert McKey M, Gaume L. 2010. Flower-scent mimicry masks a deadly trap in the carnivorous plant Nepenthes rafflesiana. J Ecol 98: 845856.

Di Giusto B, Grosbois V, Fargeas E, Marshall DJ, Gaume L. 2008. Contribution of pitcher fragrance and fluid viscosity to high prey diversity in a Nepenthes carnivorous plant from Borneo. J Biosci 33: 121-136.

Farre-Armengol G, Filella I, Llusia J, Penuelas J. 2015. Relationships among floral VOC emissions, floral rewards and visits of pollinators in five plant species of a Mediterranean shrubland. Plant Ecol Evol 148 (1): $90-99$.

Foot G, Rice SP, Millett J. 2014. Red trap colour of the carnivorous plant Drosera rotundifolia does not serve a prey attraction or camouflage function. Biol Lett 10: 20131024. DOI: 10.1098/rsbl.2013.1024

Gaume L, Bazile V, Huguin M, Bonhomme V. 2016. Different pitcher shapes and trapping syndromes explain resource partitioning in Nepenthes species. Ecol Evol 6 (5): 1378-1392. DOI: 10.1002/ece3.1920.

Green M, Horner JD. 2007. The relationship between prey capture and characteristics of the carnivorous pitcher plant, Sarracenia alta wood. Am Midl Nat 158: 424-431.

Handayani T, Latifah D, Dodo. 2005. Diversity and growth behaviour of Nepenthes (pitcher plants) in Tanjung Puting National Park, Central Kalimantan Province. Biodiversitas 6 (4): 248-252.

Handayani T. 2017. Flower morphology, floral development and insect visitors to flowers of Nepenthes mirabilis. Biodiversitas 18 (4): 16241631.

Hua Y, Lie H. 2005. Food web and fluid in pitchers of Nepenthes mirabilis in Zhuhai, China. Acta Bot Gall 152 (2): 165-175. 
Jurgens A, Witt T, Sciligo A, El-Sayed A. 2015. The effect of trap color and trap-flower distance on pray and pollinator capture in carnivorous Drosera species. Funct Ecol 29: 1026-1037.

Merbach MA, Ziska G, Fiala B,Maschwitz U, Booth W. 2001. Patterns of nectar secretion in five Nepenthes species from Brunei Darussalam, Northwest Borneo, and implications for ant-plant relationships. Flora 196: 153-160.

Moran J, Booth W, Charles J. 1999. Aspects of pitcher morphology and spectral characteristics of six Bornean Nepenthes pitcher plant species: Implications for prey capture. Ann Bot 83: 521-528.

Moran JA. 1996. Pitcher dimorphism, prey composition and the mechanisms of prey attraction in the pitcher plant Nepenthes rafflesiana in Borneo. J Ecol 84: 515-525

Newell SJ, Nastase AJ. 1998. Efficiency pitcher capture by Sarracenia purpurea (Sarraceniaceae), the northern pitcher plant. Am J Bot 85 (1): 88-91.

Owen TP, Lennon KA. 1999. Structure and development of the pitchers from the carnivorous plant Nepenthes alata (Nepenthaceae). Am J Bot 86: 1382-1390.

Pavlovič A, Masarovicova E, Hudak J. 2007. Carnivorous syndrome in Asian pitcher plants of the genus Nepenthes. Ann Bot 100 (3): 527 536. Doi:10.1093/annbot/mcm145.
Plachno BJ. 2007. Sweet but dangerous: Nectarines in carnivorous plants. Acta Agrobot 60 (2): 31-37.

Schaefer H, Rolshausen G. 2005. Plants on red alert: Do insects pay attention?. BioEssays 28: 65-71.

Schaefer HM, Ruxton GD. 2008. Fatal attraction: Carnivorous plants roll out the red carpet to lure insects. Biol Lett 4: 153-155.

Scholz I, Bückins M, Dolge I, Erlinghagen T, Weth A, Hischen F, Mayer J, Hoffmann S, Riederer M, Riedel M, Baumgartner W. 2010. Slippery surfaces of pitcher plants: Nepenthes wax crystals minimize insect attachment via microscopic surface roughness. J Exp Biol 213: 1115-1125.

Steyn WJ, Wand SFE, Holcroft DM, Jacobs G. 2002. 1Anthocyanins in vegetative tissues: a proposed unified function in photoprotection. New Phytol 155: 349-361.

Wallen MM. 2008. Effect of color,size, and density of Sarracenia purpurea on prey capture. https://deepblue.lib.umich.edu/handle/2027.42/61499

Wang L, Zhou Q, Zheng Y, Xu S. 2009. Composite structure and properties of the pitcher surface of the carnivorous plant Nepenthes and its influence on the insect attachment system. Nat Sci 19: $1657-$ 1664 . 